\title{
Effects of Parathyroid Hormone on Cytosolic Free Calcium Concentration in Individual Rabbit Connecting Tubules
}

James E. Bourdeau and Kai Lau

Divisions of Nephrology, Departments of Medicine, Michael Reese Hospital and Medical Center and University of Chicago, Chicago, Illinois 60616

\begin{abstract}
PTH stimulates active Ca reabsorption in isolated perfused rabbit kidney connecting tubules (CNTs). The existence of PTH-sensitive adenylate cyclase and the reproduction of increased epithelial Ca transport by dibutyryl-cAMP suggest that cAMP is the mediator. Accordingly, we studied the effects of PTH and 8-bromoadenosine 3',5'-cAMP (8-Br-cAMP) on cytosolic free calcium concentration $\left(\left[\mathrm{Ca}^{2+}\right]_{i}\right)$ in individual rabbit CNTs. $\left[\mathrm{Ca}^{2+}\right]_{i}$ was estimated by continuous epifluorescence microscopy of single fura-2-loaded tubules during dual wavelength excitation. In nonperfused controls at $37^{\circ} \mathrm{C},\left[\mathrm{Ca}^{2+}\right]_{i}$ decreased with time. In contrast to vehicle controls, synthetic bovine (1-34) PTH (0.1 nM) increased $\left[\mathrm{Ca}^{2+}\right]_{i}$ within $4 \mathrm{~min}$, produced a maximal effect in $7.2 \mathrm{~min}$, and sustained its effect for at least $2 \mathrm{~min}$ after washout. 8-Br-cAMP (1 mM) mimicked the effect of PTH, but with an earlier onset of action. To test the hypothesis that lumen $\mathrm{Ca}$ is the predominant source of the rise in $\left[\mathrm{Ca}^{2+}\right]$, we studied singly perfused $\mathrm{CNTs}$. In the absence of bath and lumen Ca, PTH elicited no rise in $\left[\mathrm{Ca}^{2+}\right]_{\text {i }}$, implying that intracellular $\mathrm{Ca}$ stores are not the major source. In contrast, there was a rise when $\mathrm{Ca}$ was replenished in both media. In the continuous presence of bath $\mathrm{Ca}$, lumen $\mathrm{Ca}$ was estimated to contribute $65 \%$ of the total rise in $\left[\mathrm{Ca}^{2+}\right]_{i}$ in response to PTH when it was first deleted and then replenished. However, when the sequence of lumen Ca manipulation was reversed, the contributions by lumen and bath $\mathrm{Ca}$ were found to be essentially equal. We conclude $(a)$ at a physiologic concentration, PTH increases $\left[\mathrm{Ca}^{2+}\right]_{\mathrm{i}}$ in rabbit CNTs, (b) 8-Br-cAMP mimics this action, implicating $\mathbf{c A M P}$ as a second messenger, and $(c)$ the PTH-stimulated rise in $\left[\mathrm{Ca}^{2+}\right]_{i}$ depends importantly on both bath and tubular luminal fluid $\mathrm{Ca}$.
\end{abstract}

\section{Introduction}

PTH increases Ca reabsorption by connecting tubules (CNTs) ${ }^{1}$ of the rabbit $(1,2)$. Since $\mathrm{Ca}^{2+}$ is transported against a transepithelial electrochemical potential difference $(1,2)$, it has been

Address correspondence to Dr. Kai Lau, Division of Renal Medicine, Michael Reese Hospital and Medical Center, Lake Shore Drive at 31st Street, Chicago, IL 60616.

Received for publication 21 March 1988 and in revised form 1 September 1988.

1. Abbreviations used in this paper: 8-Br-cAMP, 8-bromoadenosine $3^{\prime}, 5^{\prime}$-cAMP; $\left[\mathrm{Ca}^{2+}\right]_{i}$, cytosolic free calcium concentration; CNT(s), connecting tubule(s); $R$, ratio of net fluorescence emitted at $500 \mathrm{~nm}$ for

J. Clin. Invest.

(c) The American Society for Clinical Investigation, Inc.

0021-9738/89/02/0373/07 \$2.00

Volume 83, February 1989, 373-379 inferred that this absorption is active and occurs via a cellular pathway (3). Definitive evidence for and analysis of a presumed transcellular route of $\mathrm{Ca}^{2+}$ movement from lumen to bath are lacking, in part because of difficulties in measuring cytosolic free calcium concentration $\left(\left[\mathrm{Ca}^{2+}\right]_{\mathrm{i}}\right)$. One model of a cellular pathway for epithelial $\mathrm{Ca}$ transport would predict a rise in $\left[\mathrm{Ca}^{2+}\right]_{i}$ in response to PTH (4). The availability of fura-2, an intracellular $\mathrm{Ca}^{2+}$-sensitive fluorescent dye, has made it possible for us to investigate this thesis in freshly dissected individual rabbit CNTs that were suffused continuously with a physiologic solution in vitro. We found that $\left[\mathrm{Ca}^{2+}\right]_{i}$ increased 2-4 min after exposure to PTH. We reasoned that if the PTH-induced elevation in $\left[\mathrm{Ca}^{2+}\right]_{\mathrm{i}}$ is related to its $\mathrm{Ca}$ transport effects, another agent known to mimic such actions also should increase $\left[\mathrm{Ca}^{2+}\right]_{i}$. Given the PTH-sensitive adenylate cyclase in rabbit CNTs (5) and the stimulatory effect of dibutyryl-cAMP on Ca transport in this nephron segment (2), we examined the effects of 8-bromoadenosine $3^{\prime}, 5^{\prime}$-cAMP (8-BrcAMP). The results implicate cAMP as a messenger. Hypothetically, if the rise in $\left[\mathrm{Ca}^{2+}\right]_{i}$ is related to the known stimulation of $\mathrm{Ca}$ reabsorption by these agonists, lumen $\mathrm{Ca}$ ought to be the predominant source. To test this hypothesis, experiments were performed in singly perfused CNTs in which we manipulated lumen and bath $\mathrm{Ca}$. Contrary to the above prediction, our results demonstrate that bath $\mathrm{Ca}$ is equally as important as lumen $\mathrm{Ca}$ in causing the PTH-induced rise in $\left[\mathrm{Ca}^{2+}\right]_{i}$.

\section{Methods}

Female albino rabbits, $0.9-1.2 \mathrm{~kg}$, were fed a nutritionally complete synthetic diet containing $0.9 \% \mathrm{Ca}, 0.4 \% \mathrm{P}$, and $60 \mathrm{IU}$ vitamin $\mathrm{D}_{3} / 100 \mathrm{~g}$ of feed (6) until each gained at least $200 \mathrm{~g}$. They were decapitated and the left kidney was excised. Blood was collected from vessels of the neck for analyses.

Individual tubules were dissected and studied in vitro in simple electrolyte solutions. Unless stated otherwise, these contained (in millimolar): $\mathrm{CaCl}_{2}, 2 ; \mathrm{NaCl}, 148.5 ; \mathrm{NaH}_{2} \mathrm{PO}_{4}, 2.0 ; \mathrm{KCl}, 5 ; \mathrm{MgSO}_{4}, 1.2$; D-glucose, 5.6; and L-alanine, 6.0. $\mathrm{CaCl}_{2}$ was replaced isosmotically with $\mathrm{NaCl}$ in $\mathrm{Ca}$-free solutions. The EGTA solution for the minimal value of $R$ (ratio of net fluorescence emitted at $500 \mathrm{~nm}$ for excitation wavelengths of 340 and $380 \mathrm{~nm}$, respectively) measured in the absence of $\mathrm{Ca}\left(R_{\min }\right)$ and the $2.5-\mathrm{mM}$ Ca solution for the maximal value of $R$ measured in the presence of saturating $\mathrm{Ca}\left(R_{\max }\right)$ were identical to the standard solutions except that $\mathrm{CaCl}_{2}$ was replaced by 2 mM EGTA in the former and by $2.5 \mathrm{mM} \mathrm{CaCl}_{2}$ in the latter. Each solution was titrated to a pH of 7.40 with $1 \mathrm{M} \mathrm{NaOH}$ and bubbled for $15 \mathrm{~min}$ with $100 \% \mathrm{O}_{2} . \mathrm{Na}, \mathrm{K}$, and $\mathrm{Ca}$ and osmolality were measured in all solutions (7).

A thin slice of the kidney was immersed in chilled $\left(4^{\circ} \mathrm{C}\right)$ dissection solution containing $1 \mathrm{mg} / \mathrm{ml}$ of defatted BSA. The medulla was am-

excitation wavelengths of 340 and $380 \mathrm{~nm}$, respectively; $R_{\min }$, minimal value of $R$ measured in the absence of $\mathrm{Ca} ; R_{\max }$, maximal value of $R$ measured in the presence of saturating $\mathrm{Ca}$. 
putated and the cortex was microdissected (at $20-22^{\circ} \mathrm{C}$ ) under a stereomicroscope. CNTs were teased from the cortical labyrinth. They were identified (Fig. 1) by their location adjacent to interlobular arteries, their attachment to distal convoluted tubules or arcades, and their characteristic size and microscopic appearance.

$\left[\mathrm{Ca}^{2+}\right]_{\mathrm{i}}$ was measured with fura-2 as described by Tsien et al. (8). Fura-2-AM (Molecular Probes, Inc., Eugene, OR) was dissolved in DMSO and stored at $-20^{\circ} \mathrm{C}$ in a desiccator. Isolated CNTs were incubated in a $5-\mu \mathrm{M}$ fura-2-AM solution and loaded at $20-22^{\circ} \mathrm{C}$ for 4.5-7.5 h. A fluorometer system (Spex Industries, Inc., Edison, NJ) was interfaced with a modified Diaphot inverted microscope (Nikon, Inc., Garden City, NY). Exciting radiation was split between two monochromators, each with entrance and exit slits of $1.8 \mathrm{~nm}$. One beam at $\lambda=340 \mathrm{~nm}$ and another at $\lambda=380 \mathrm{~nm}$ were alternately directed by a reflective chopper into the nosepiece of the microscope. The incoming beams were reflected into a UV-F $40 \times$, glycerin immersion, objective lens (Nikon, Inc.; numerical aperture $=1.30$ ) by a 400-nm dichroic mirror. Epifluorescence from the tubule was collected by the same objective lens and passed through the dichroic mirror and a 420 -nm barrier filter. It was projected by a $1 \times$ lens through a rectangular aperture and an interference filter (500-nm peak, 20-30-nm bandwidth) onto a photon-counting detector (Hamamatsu Photonics K.K., Shizuoka, Japan).

A black aluminum suffusion chamber (White Instrument Co., Suitland, MD) was mounted on the stage of the microscope and water-jacketed to $37^{\circ} \mathrm{C}$. The tubule was suffused continuously at 2 $\mathrm{ml} / \mathrm{min}$ with a syringe pump. Solutions were prewarmed and temperatures were controlled between 36.7 and $37.1^{\circ} \mathrm{C}$. The effluent bathing medium was aspirated continuously. The bottom of the chamber was a 0.15 -mm-thick quartz coverslip. The suffusion apparatus was surrounded by a black enclosure, and during fluorescence measurements the room was illuminated solely with red light.

Nonperfused tubules. Fura-2-loaded CNTs were transferred to the suffusion chamber, which contained $\sim 0.5 \mathrm{ml}$ of $2-\mathrm{mM} \mathrm{Ca}$ solution at room temperature. After the tubule was mounted and immobilized on the coverslip with glass micropipettes it was flushed with $25 \mathrm{ml}$ of the suffusate to remove residual dye. When the temperature reached $37^{\circ} \mathrm{C}$, final positioning and focusing were performed. Fluorescence at 500 $\mathrm{nm}$ of an $\sim 200 \times 40 \mu \mathrm{m}$ region of the tubule was measured continuously and integrated every $0.5 \mathrm{~s}$. From each kidney, three to six CNTs unexposed to fura-2-AM were studied identically to measure autofluorescence.

In time controls fluorescence was measured for $80-90 \mathrm{~min}$ at $37^{\circ} \mathrm{C}$ during continuous suffusion with $2-\mathrm{mM} \mathrm{Ca}$. Thereafter, a calibration was performed in situ by changing the suffusate sequentially to 2-mM EGTA for $5 \mathrm{~min}, 2-\mathrm{mM}$ EGTA $+5-\mu \mathrm{M}$ ionomycin until $R_{\min }$ was reached, and $2.5-\mathrm{mM} \mathrm{Ca}$ until $R_{\max }$ was obtained. With PTH, 8-BrcAMP, or acetic acid, fluorescence was first measured for $14 \pm 1$ min after reaching $37^{\circ} \mathrm{C}$ while the tubule was suffused with $2-\mathrm{mM} \mathrm{Ca}$ solution to provide baseline data. Thereafter, the tubule was exposed to the agonist or reagent in the same suffusate for $10 \mathrm{~min}$, followed by a

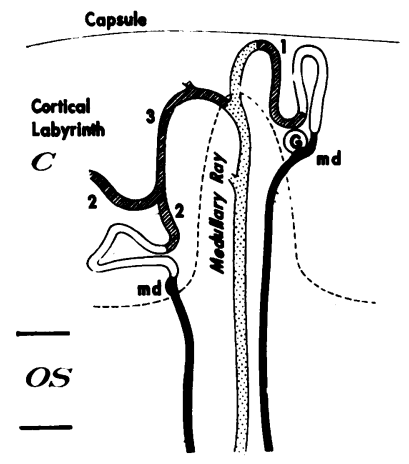

Figure 1. Locations from which connecting tubules were dissected: (1) subcapsular CNT not associated with arcades; (2) initial portion of CNT within mid- and deep-cortical arcades; and (3) joining segments between the branch points within arcades. Solid, white, and stippled structures represent thick ascending limbs of Henle's loop, distal convoluted tubules, and cortical collecting ducts, respectively. $C$, cortex; $O S$, outer stripe of the outer medulla; $G$, glomerulus; $m d$, macula densa. 5-min recovery period. In three rabbits we studied an acetic acid control and a PTH-treated tubule from the same kidney.

Perfused tubules. Fura-2-loaded CNTs were studied similarly to nonperfused tubules with two differences. First, the lumen was cannulated and perfused at $\sim 75 \mathrm{nl} / \mathrm{min}$ by gravity flow (9). Perfusate composition was changed without interrupting perfusion (10). The general protocol is shown in Fig. 7. Baseline $\left[\mathrm{Ca}^{2+}\right]_{i}$ was measured for $10 \mathrm{~min}$ at $37^{\circ} \mathrm{C}$, during which both perfusate and suffusate contained $2-\mathrm{mM}$ $\mathrm{Ca}$. Thereafter, $\mathrm{Ca}$ was deleted from the lumen. After $10 \mathrm{~min}, 0.1 \mathrm{nM}$ PTH was added to the suffusate. After an additional $10 \mathrm{~min}$, luminal Ca was restored in the continued presence of PTH. Finally, PTH was withdrawn, followed by a $30-\mathrm{min}$ recovery period with $2-\mathrm{mM} \mathrm{Ca}$ in both perfusate and suffusate. Second, during the calibration period the lumen also was perfused with $2 \mathrm{mM}$ EGTA followed by $2 \mathrm{mM} \mathrm{Ca}$ for measurements of $R_{\min }$ and $R_{\max }$, respectively. Ionomycin was absent from all of these perfusates. Controls were studied identically but without PTH. In experiments to assess the role of intracellular $\mathrm{Ca}$ stores, both suffusate and perfusate $\mathrm{Ca}$ were deleted for $20 \mathrm{~min}$ after the baseline period. In all figures of perfused CNTs the times of perfusate exchanges, $4.5 \pm 0.25 \mathrm{~min}$, were omitted for clarity. Net fluorescence was calculated by subtracting the autofluorescence of nonloaded tubules dissected from the same kidney.

Synthetic bovine PTH 1-34 tetratriacontapeptide (Peninsula Laboratories, Inc., Belmont, CA) was dissolved in $10 \mathrm{mM}$ acetic acid and lyophilized. Aliquots were stored in a desiccator at $-20^{\circ} \mathrm{C}$. 8-Br-cAMP was obtained from Sigma Chemical Co., Șt. Louis, MO; EGTA, puriss P.A., from Fluka AG, Buchs, Switzerland; and ionomycin from Calbiochem-Behring Corp., San Diego, CA.

$\left[\mathrm{Ca}^{2+}\right]_{\mathrm{i}}$ was calculated as (11): $\left[\mathrm{Ca}^{2+}\right]_{\mathrm{i}}=K_{\mathrm{d}}\left(R-R_{\min } / R_{\max }\right.$ $-R)\left(\mathrm{F}_{0} / \mathrm{F}_{\mathrm{s}}\right) . K_{\mathrm{d}}$, the dissociation constant of the fura-2:Ca complex at $37^{\circ} \mathrm{C}$, was assumed to be $224 \mathrm{nM}(11) . \mathrm{F}_{0} / \mathrm{F}_{\mathrm{s}}$ is the ratio of net fluorescence at $\lambda=380 \mathrm{~nm}$ excitation for $R_{\min }$ to that for $R_{\max }$.

The tracings in Figs. 2-6 and 8 represent 10-s averages. The absolute values of $\left[\mathrm{Ca}^{2+}\right]_{\mathrm{i}}$ in Table I represent averages during the indicated time intervals.

Statistical comparisons were made by analysis of variance of repeated measures (12) or by paired or unpaired $t$ test (13) as appropriate. $P$ values $<0.05$ were considered to be significant.

\section{Results}

\section{Nonperfused CNTs}

These studies demonstrate the feasibility of measuring $\left[\mathrm{Ca}^{2+}\right]_{\mathrm{i}}$ with fura-2 in individual microdissected rabbit CNTs. At a suffusion rate of $2 \mathrm{ml} / \mathrm{min}$, it is unlikely that any extracellular fura-2 that might have resulted from leakage out of the cells would contribute significantly to the measured fluorescence.

\section{TIME CONTROLS}

The autofluorescence was similar whether it was studied before or after fura-2-loaded tubules on a given day. In a few unloaded tubules evaluated extensively autofluorescence was stable for 80-100 min and was essentially unaffected by either agonists or reagents.

Morphologically the tubules appeared intact throughout the entire experiment, irrespective of exposure to PTH or 8-Br-cAMP. The functional integrity of the cells was evidenced by the return of $\left[\mathrm{Ca}^{2+}\right]_{i}$, with time at $37^{\circ} \mathrm{C}$ (Fig. 2), to values reported in other kidney cells (14-23).

Although body weights, food intake, blood $\mathrm{pH}$, and serum ionized [Ca] values (not shown) of the rabbits from which these CNTs had been dissected were comparable, individual tubules varied considerably in their basal $\left[\mathrm{Ca}^{2+}\right]_{\mathrm{i}}$. After several hours of exposure to the loading medium at $20-22^{\circ} \mathrm{C}$ in vitro, estimated $\left[\mathrm{Ca}^{2+}\right]_{i}$ was initially higher than the apparent 


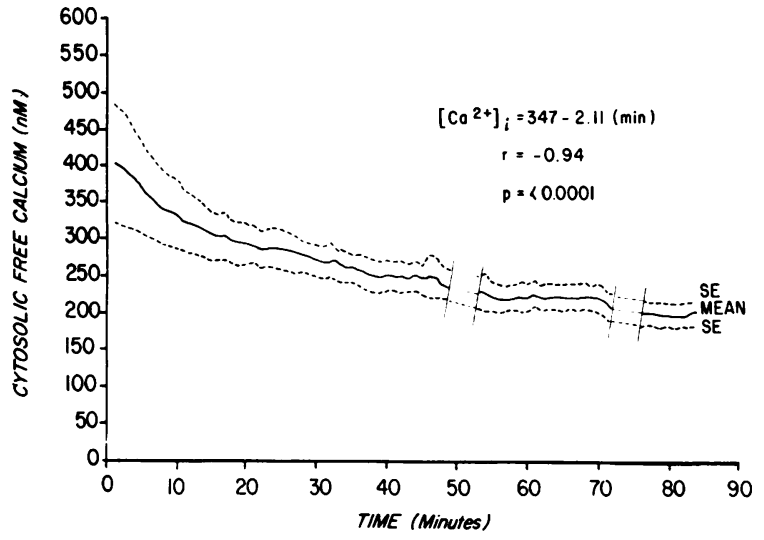

Figure 2. Time control in nonperfused tubules: $\left[\mathrm{Ca}^{2+}\right]_{\mathrm{i}}$ in CNTs $(n$ $=6$ ) as a function of time after reaching $37^{\circ} \mathrm{C}$. Interrupted areas bracketed by two vertical bars represent periods during which computer files were changed and data were not saved.

steady-state value of $\sim 200 \mathrm{nM}$ attained after equilibration at $37^{\circ} \mathrm{C}$ in time-control tubules (Fig. 2). The progressive decline was a direct function of time after having reached $37^{\circ} \mathrm{C}$, with the $\left[\mathrm{Ca}^{2+}\right]_{\mathrm{i}}(\mathrm{nM})=347-2.11(\mathrm{~min}), r=-0.94, P<0.0001$. Our results suggest that absolute values for resting $\left[\mathrm{Ca}^{2+}\right]_{i}$ are relevant and interpretable only under defined experimental conditions, notably temperature.

EFFECTS OF PTH (FIG. 3)

In six tubules treated with $10 \mu \mathrm{M}$ acetic acid, the vehicle for PTH, mean $\left[\mathrm{Ca}^{2+}\right]_{\mathrm{i}}$ tended to fall from a basal value of $267 \pm 18$ to $251 \pm 14 \mathrm{nM}$ after $10 \mathrm{~min}$ of suffusion. In contrast, $0.1 \mathrm{nM}$ PTH increased $\left[\mathrm{Ca}^{2+}\right]_{\mathrm{i}}$ from a mean value of $278 \pm 35$ to $311 \pm 36 \mathrm{nM}(\Delta=33 \mathrm{nM}, P<0.01)$ within $4 \mathrm{~min}$, and by $7 \mathrm{~min}$ a maximal increment of $68 \mathrm{nM}(P<0.005)$ was attained (Fig. 3). The effects of PTH were sustained at least $2 \mathrm{~min}$ beyond the removal of hormone from the suffusate, with an average increase in $\left[\mathrm{Ca}^{2+}\right]_{i}$ of $40 \mathrm{nM}$ during the 4-min postexposure period, similar to the increment of $36 \mathrm{nM}$ during the entire 10 min of PTH administration.

EFFECTS OF 8-Br-cAMP (FIG. 4)

To examine the potential role of adenylate cyclase, we added 8-Br-cAMP to the suffusate (Fig. 4). Suffusates without any cAMP, administered to six other tubules, were associated with a tendency for $\left[\mathrm{Ca}^{2+}\right]_{\mathrm{i}}$ to fall during this 10 -min period. $8-\mathrm{Br}$ cAMP mimicked the effects of PTH, increasing $\left[\mathrm{Ca}^{2+}\right]_{i}$ within the first $2 \mathrm{~min}$ of exposure $(\Delta=31 \mathrm{nM}, P<0.001)$, and by 6

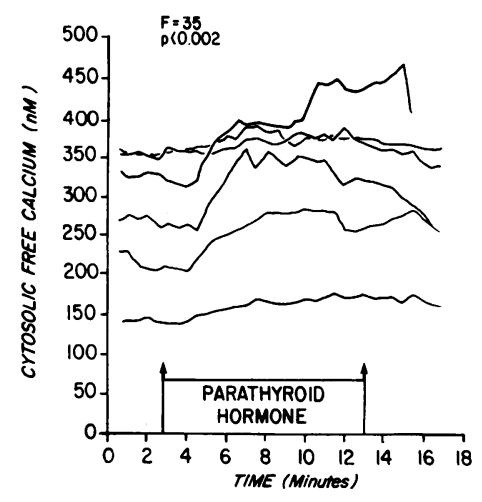

Figure 3. Response of $\left[\mathrm{Ca}^{2+}\right]_{\mathrm{i}}$ to PTH $\left(1 \times 10^{-10}\right.$ M) administered over 10 min, as indicated between arrows, in nonperfused CNTs. Each tracing represents an individual tubule.

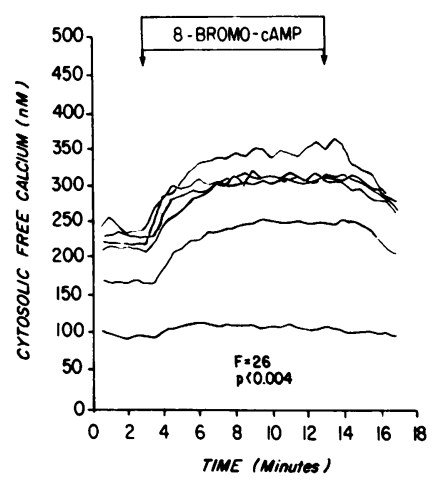

min a maximal increment of $84 \mathrm{nM}(P<0.005)$ was attained (Fig. 5). Similar to PTH, the effects of 8-Br-cAMP were sustained beyond the 10 -min exposure: the mean increment in $\left[\mathrm{Ca}^{2+}\right]_{\mathrm{i}}$ during the 4-min postexposure $(\Delta=61 \mathrm{nM})$ was comparable to the average increment during the entire $10 \mathrm{~min}$ of infusion $(\Delta=64 \mathrm{nM})$.

\section{Perfused CNTs}

SOURCES OF PTH-STIMULATED INCREMENTS IN $\left[\mathrm{Ca}^{2+}\right]_{\mathrm{i}}$ Role of intracellular Ca stores (Fig. 6). Deletion of Ca from both the bath and lumen reduced $\left[\mathrm{Ca}^{2+}\right]_{i}$ from mean baseline values of $146 \pm 18 \mathrm{nM}$ (averaged over the first $5 \mathrm{~min}$ ) and $139 \pm 18 \mathrm{nM}$ (the second $5 \mathrm{~min}$ ) to $70 \pm 17 \mathrm{nM}$ and $58 \pm 15 \mathrm{nM}$ $(P<0.05)$, respectively (Fig. 6). In the absence of media $\mathrm{Ca}$, PTH produced no rise in $\left[\mathrm{Ca}^{2+}\right]_{i}$, which tended to fall during the first $(51 \pm 14 \mathrm{nM})$ and second $(53 \pm 16 \mathrm{nM}) 5$-min periods of PTH exposure. In contrast, with $2 \mathrm{mM} \mathrm{Ca}$ in both the suffusate and perfusate, PTH promptly raised $\left[\mathrm{Ca}^{2+}\right]_{i}$ to $219 \pm 57$ $\mathrm{nM}$ and $231 \pm 53 \mathrm{nM}$, respectively, in two subsequent 5-min periods. For the second 5 -min period the increment was $177 \pm 38 \mathrm{nM}$ when compared with the corresponding period in the preceding $\mathrm{Ca}$-deletion phase $(P<0.05)$. Despite withdrawal of PTH the increase in $\left[\mathrm{Ca}^{2+}\right]_{i}$ persisted for another 5 $\min (237 \pm 55 \mathrm{nM})$, followed by a progressive decline, respectively, to $200 \pm 54,154 \pm 44,143 \pm 40,124 \pm 34$, and $121 \pm 31 \mathrm{nM}$ in the ensuing consecutive 5 -min periods (Fig. 6). Thus, similar to nonperfused tubules, PTH also increased $\left[\mathrm{Ca}^{2+}\right]_{\mathrm{i}}$ in perfused CNTs. Importantly, this effect was absent when Ca was deleted from the media.

In two CNTs we suffused $5 \mu \mathrm{M}$ ionomycin after similar durations of media $\mathrm{Ca}$ deletion to assess whether intracellular $\mathrm{Ca}$ stores were intact under these conditions. The Ca-sensitive fluorescence ratio [340:380] rose with ionomycin (from 0.58 to 0.63 in one tubule and from 0.58 to 0.67 in another) despite

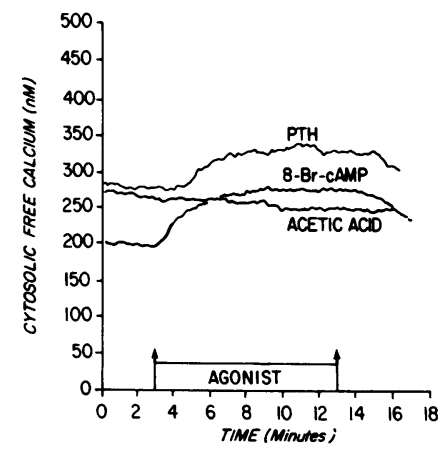

Figure 5. Comparison of the effects of PTH and 8-Br-cAMP to the acetic acid control. Each tracing represents the mean of each group of six nonperfused CNTs. 


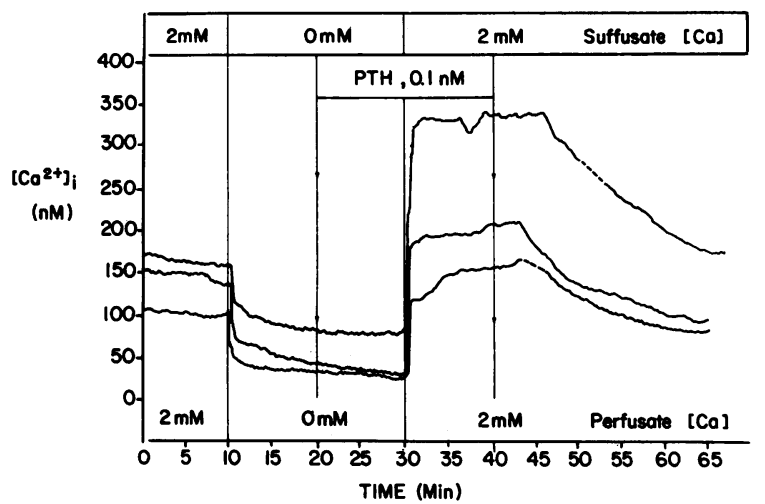

Figure 6. Effect of PTH on $\left[\mathrm{Ca}^{2+}\right]_{i}$ in the absence and presence of $\mathrm{Ca}$ in the extracellular fluids. Each tracing represents an individual perfused tubule.

continued media $\mathrm{Ca}$ omission, arguing indirectly against depletion of intracellular $\mathrm{Ca}$ stores as the reason for a lack of response to PTH.

Roles of lumen and bath Ca (Figs. 7 and 8, Table I). By manipulating lumen $\mathrm{Ca}$ we evaluated the contributions of lumen and bath $\mathrm{Ca}$ (Fig. 7). During the two consecutive 5-min baseline periods, mean $\left[\mathrm{Ca}^{2+}\right]_{i}$ 's were comparable between the control and PTH groups (Fig. 8). Selective deletion of lumen Ca reduced mean $\left[\mathrm{Ca}^{2+}\right]_{\mathrm{i}}$ by 44 and $50 \mathrm{nM}$, respectively. Despite the continued absence of lumen $\mathrm{Ca}$, PTH significantly increased $\left[\mathrm{Ca}^{2+}\right]_{i}$ by $24 \pm 6 \mathrm{nM}$ in the second 5 -min period, whereas $\left[\mathrm{Ca}^{2+}\right]_{\mathrm{i}}$ tended to decline in the controls. Their divergent changes were highly significant. When $2 \mathrm{mM} \mathrm{Ca}$ was reintroduced in the perfusate, PTH produced a prompt additional increment in $\left[\mathrm{Ca}^{2+}\right]_{i}$. This was sustained not only throughout the $10 \mathrm{~min}$ of exposure, but also for $5 \mathrm{~min}$ after PTH withdrawal. In control tubules lumen $\mathrm{Ca}$ repletion caused a numerical rise in $\left[\mathrm{Ca}^{2+}\right]_{\mathbf{i}}(0.05<P<0.10)$. This was followed by a steady and continuous decline in the ensuing 30 min, similar to the nonperfused time-control tubules (Fig. 2).

Estimates of the contribution by bath $\mathrm{Ca}$. The tendency for $\left[\mathrm{Ca}^{2+}\right]_{\mathrm{i}}$ in control tubules to fall during lumen $\mathrm{Ca}$ deletion beyond the first $10 \mathrm{~min}$ (Table I) suggests that the increment in PTH-treated tubules, observed under identical conditions,

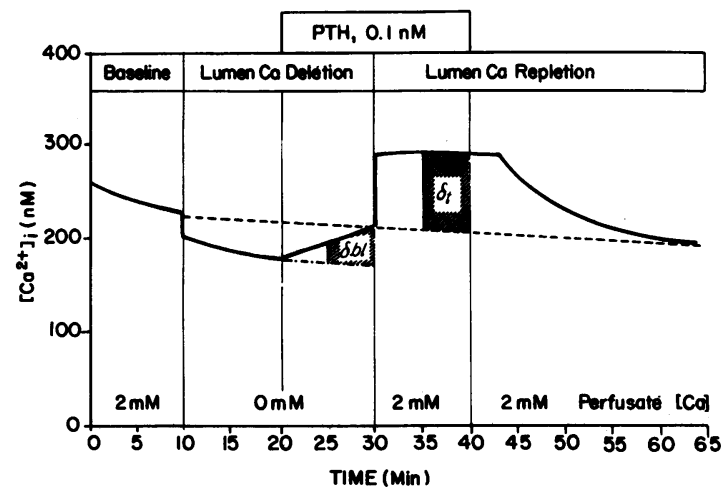

Figure 7. Paradigm of the protocol for experiments in perfused CNTs. Cytosolic free Ca concentration (plotted against time) in isolated tubules treated with PTH. $\delta_{t}$, increment in $\left[\mathrm{Ca}^{2+}\right]_{i}$ due to PTH in the presence of 2-mM Ca in both lumen and bath. $\delta_{\mathrm{b}}$, increment in $\left[\mathrm{Ca}^{2+}\right]_{\mathrm{i}}$ due to PTH in the presence of $\mathrm{Ca}$ in the bath only.

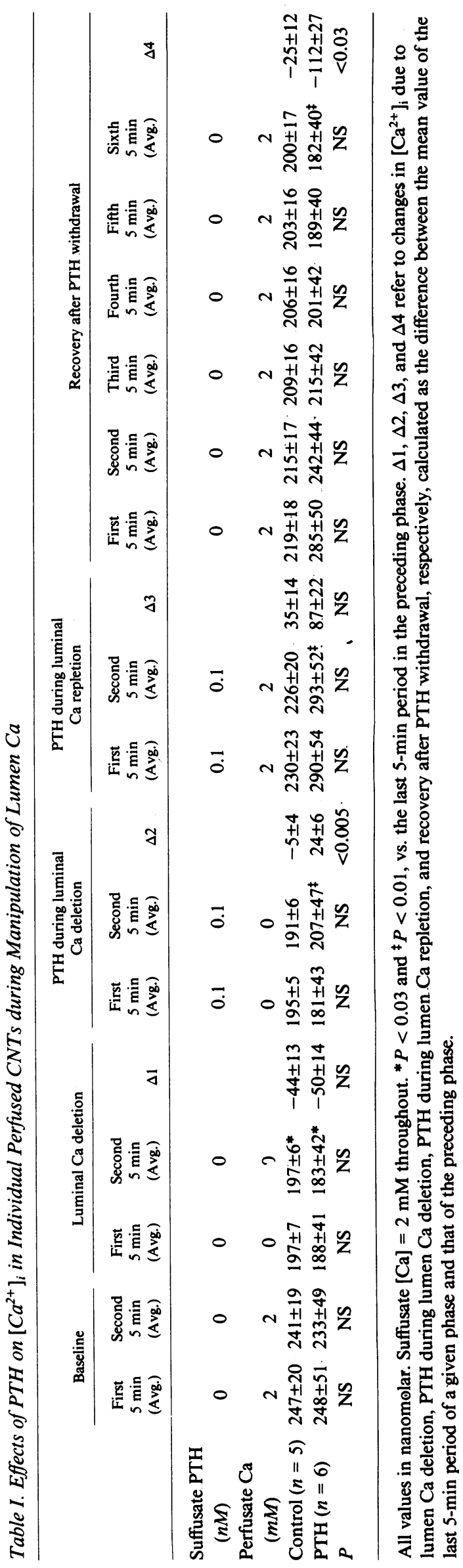




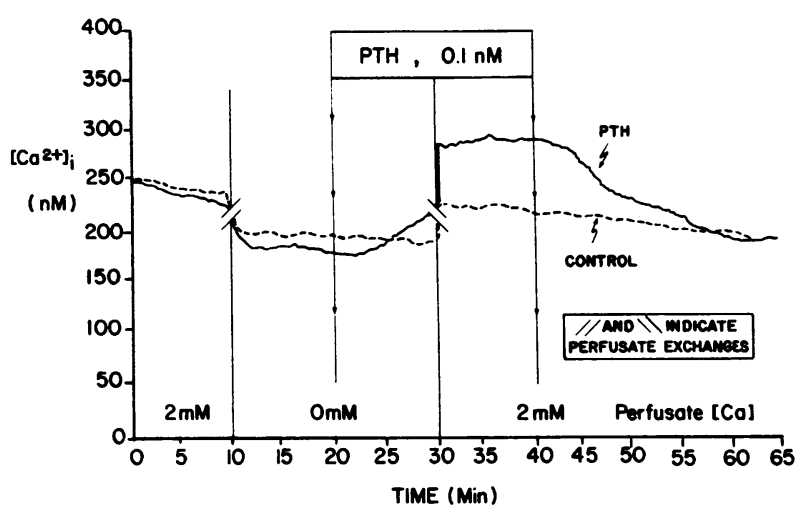

Figure 8. Response of $\left[\mathrm{Ca}^{2+}\right]_{\mathrm{i}}$ to PTH in the absence and presence of luminal $\mathrm{Ca}$ in singly perfused CNTs. Suffusate $[\mathrm{Ca}]=2 \mathrm{mM}$ throughout. The tracings represent the means for six PTH-treated and five time-control CNTs.

probably underestimated the contribution by bath Ca. Specifically, the calculated increment of $24 \mathrm{nM}$ induced by PTH in the absence of lumen $\mathrm{Ca}$ assumed a steady value of $183 \mathrm{nM}$, as in the pre-PTH phase (Table I). This increment should be augmented by adjusting for the concomitant, though small, fall associated with sustained luminal $\mathrm{Ca}$ deletion, demonstrable in control but not in PTH-treated CNTs.

By extrapolating a linear regression (using 30 consecutive 10-s average $\left[\mathrm{Ca}^{2+}\right]_{\mathrm{i}}$ values) from the last 5 -min period of the second phase into the third phase (i.e., dotted line between minutes 20 and 30, as illustrated in Fig. 7), we derived a predicted value of $174 \pm 41 \mathrm{nM}$ if no hormone had been given to PTH-treated tubules. After this adjustment the average increment in $\left[\mathrm{Ca}^{2+}\right]_{\mathrm{i}}$ stimulated by PTH in the absence of lumen $\mathrm{Ca}$, and hence attributable to bath $\mathrm{Ca}\left(\delta_{\mathrm{bl}}\right.$ in Fig. 7$)$, was $33 \pm 8$ $\mathrm{nM}$ (derived from the difference between the observed result of $207 \pm 47$ [Table I] and the predicted value of $174 \pm 41 \mathrm{nM}$ ). This is greater than the similarly derived difference $(-7 \pm 4 \mathrm{nM} ; P$ $<0.005$ ) in control tubules manipulated identically but not exposed to PTH.

Estimates of the total increments in $\left[\mathrm{Ca}^{2+}\right]_{i}$ due to PTH in the presence of bath and lumen $\mathrm{Ca}$. To derive these estimates a baseline value of $\left[\mathrm{Ca}^{2+}\right]_{\mathrm{i}}$ temporally corresponding to no hormone treatment in the same tubules $(200 \pm 43 \mathrm{nM})$ was obtained by interpolation between values measured during the last $5 \mathrm{~min}$ of the baseline and recovery phases (Fig. 7, dashed line). The total increment due to PTH $\left(\delta_{t}\right.$ in Fig. 7) was $94 \pm 22$ $\mathrm{nM}$, derived from the difference between the observed result of $293 \mathrm{nM}$ (Table I) and this predicted value of $200 \mathrm{nM}$. This is greater than the similarly derived difference $(8 \pm 8 \mathrm{nM} ; P$ $<0.01$ ) in control tubules manipulated identically but not treated with PTH.

Estimates of the contribution by lumen $\mathrm{Ca}$. Because our results (Fig. 6) suggested a negligible role for intracellular $\mathrm{Ca}$ stores in mediating the PTH-induced rise in $\left[\mathrm{Ca}^{2+}\right]_{i}$, the total increment in $\left[\mathrm{Ca}^{2+}\right]_{i}$ was resolved into two components: that due to bath $\mathrm{Ca}$ and that due to lumen $\mathrm{Ca}$. Subtraction of the bath $\mathrm{Ca}$ component from the total provides an estimate of the lumen $\mathrm{Ca}$ component, $61 \pm 16 \mathrm{nM}$, which is greater than that found in controls, $14 \pm 6 \mathrm{nM}(P<0.04)$. Analysis of data derived by this protocol suggests a greater contribution by lumen $\mathrm{Ca}$ than by bath $\mathrm{Ca}$ (61 vs. $33 \mathrm{nM}$ ). However, in two additional perfused CNTs in which the PTH-induced increment in
$\left[\mathrm{Ca}^{2+}\right]_{\mathrm{i}}$ was measured first in the presence of perfusate $\mathrm{Ca}$ and then in its absence, we found the contributions of lumen and bath $\mathrm{Ca}$ to be very similar (mean of 31 vs. $35 \mathrm{nM}$, respectively).

\section{Discussion}

We found that at concentrations similar to values seen in $\mathrm{Ca}$ or vitamin D-deprived rabbits $(6,24)$ PTH causes a sustained but reversible increase in $\left[\mathrm{Ca}^{2+}\right]_{i}$ in rabbit CNT cells. $8-\mathrm{Br}-$ cAMP mimics PTH, but with an earlier onset of action, consistent with a messenger role for cAMP. Our studies demonstrate the feasibility of measuring $\left[\mathrm{Ca}^{2+}\right]_{i}$ with fura- 2 in freshly dissected rabbit CNTs. During equilibration at $37^{\circ} \mathrm{C},\left[\mathrm{Ca}^{2+}\right]_{\mathrm{i}}$ fell to levels reported in other kidney cells $(14-23,25)$. The slightly higher resting $\left[\mathrm{Ca}^{2+}\right]_{\mathrm{i}}$ in CNTs might be explained by differences in species, methods of harvesting cells, nephron sites, and protocols, among others.

The effects of PTH on $\left[\mathrm{Ca}^{2+}\right]_{\mathrm{i}}$ have been examined in other kidney-derived tissues $(14,19-21,26)$. Except for two studies $(21,22)$, PTH was reported to increase $\left[\mathrm{Ca}^{2+}\right]_{\mathrm{i}}$. Qualitatively the increase in $\left[\mathrm{Ca}^{2+}\right]_{\mathrm{i}}$ produced by PTH in the CNT is similar to these observations, since $0.1 \mathrm{nM}$ PTH also elicited an effect in cultured proximal tubule cells $(14,20)$.

There are, however, several differences. First, the onset of PTH action in CNTs (requiring 4 min of exposure) was slower than the response (within seconds) in proximal tubules $(14,19$, $20,26)$. Second, studies in proximal tubules $(19,20,26)$ using a superfusion apparatus and epifluorescence microscope (19) suggest a transient $1-(20)$ to $3-\min (26)$ spike in $\left[\mathrm{Ca}^{2+}\right]_{i}$ despite continued hormone exposure. In contrast, the PTH effect in CNTs was sustained during prolonged exposure and persisted 3 to 4 min after removal (Figs. 5, 6, and 8). Third, contrary to proximal tubule cells $(14,26), 8-\mathrm{Br}$-cAMP mimicked PTH in the CNT, similar to the increased ${ }^{45} \mathrm{Ca}$ uptake by cultured monkey kidney cells when exposed to either PTH or dibutyryl-cAMP $(27,28)$. In the proximal tubule cells neither dibutyryl-cAMP, 3-isobutyl-1-methylxanthine, nor forskolin reproduced the effects of PTH (14). These divergent responses to cAMP analogues may reflect differences in species, cell preparation, experimental protocol, or origin and function of the nephron segment. In addition, it is possible that PTH raises $\left[\mathrm{Ca}^{2+}\right]_{\mathrm{i}}$ by both cAMP-dependent and -independent mechanisms, similar to PTH-sensitive osteosarcoma cells (29). The former produced a delayed but sustained rise in $\left[\mathrm{Ca}^{2+}\right]_{\mathrm{i}}$ related directly to intracellular cAMP concentration. The latter caused a rapid but short-lived (1-min) rise in $\left[\mathrm{Ca}^{2+}\right]_{i}$. In proximal tubules an immediate stimulatory effect of PTH on the hydrolysis of phosphatidylinositol 4,5-bisphosphate produces a rapid rise in inositol 1,4,5-trisphosphate and diacylglycerol, which are postulated to release intracellular $\mathrm{Ca}$ and elicit a 60-s $\mathrm{Ca}$ transient (20). These effects were not mimicked by cAMP. Despite the 0.5-s resolution of our measurement system we did not observe a spike response to PTH in the CNT. The delayed and sustained increase in $\left[\mathrm{Ca}^{2+}\right]_{\mathrm{i}}$ in the $\mathrm{CNT}$ was, therefore, more comparable to the cAMP-dependent rise in $\left[\mathrm{Ca}^{2+}\right]_{i}$ in osteosarcoma cells (29) and to the increased ${ }^{45} \mathrm{Ca}$ uptake in cultured kidney cells (28). Finally, it is possible that effects of PTH to alter solute transport and to signal cellular metabolism are mediated by different mechanisms. For example, gluconeogenesis (30) and membrane topography (31) may be al- 
tered by PTH using $\left[\mathrm{Ca}^{2+}\right]_{\mathrm{i}}$ as a messenger, whereas inhibition of $\mathrm{Na}: \mathrm{H}$ exchange, $\mathrm{Na}$-dependent phosphate uptake, and increased absorptive $\mathrm{Ca}$ flux may be mediated by cAMP and thus reproducible by cAMP analogues $(2,21,32-37)$, forskolin (32), and 3-isobutyl-1-methylxanthine (32). In isolated perfused proximal convoluted tubules, increasing $\left[\mathrm{Ca}^{2+}\right]_{\mathrm{i}}(23)$ by raising bath [Ca] did not alter lumen-to-bath phosphate flux (38), whereas the same maneuver stimulated gluconeogenesis (38).

The distal nephron is the primary site regulating $\mathrm{Ca}$ excretion (37, 39-42). The CNT is the most distal rabbit nephron segment demonstrating PTH-stimulated Ca reabsorption (2), which presumably occurs transcellularly. Hypothetically, if the stimulatory action of PTH on Ca transport is related to the increase in $\left[\mathrm{Ca}^{2+}\right]_{\mathrm{i}}$ that we observed, lumen $\mathrm{Ca}$ ought to be the predominant contributor. Though our estimates indicate that bath $\mathrm{Ca}$ contributes substantially, lumen $\mathrm{Ca}$ does account for $50-65 \%$ of the PTH-induced increment in $\left[\mathrm{Ca}^{2+}\right]_{i}$, consistent with the above hypothesis.

A finding inconsistent with this hypothesis, however, was the increase in $\left[\mathrm{Ca}^{2+}\right]_{i}$ caused by PTH in the absence of lumen $\mathrm{Ca}$ (Fig. 8), implying that basolateral membrane $\mathrm{Ca}$ entry is also stimulated. Although this component was smaller than that due to lumen $\mathrm{Ca}$ when estimated by perfusing the tubule with zero $\mathrm{Ca}$ first, it was comparable when estimated by reversing the sequence of manipulation. The physiologic role of basolateral $\mathrm{Ca}$ entry is presently unknown, because it is in a direction opposite to PTH-stimulated Ca reabsorption. We speculate that it may "prime" basolateral plasma membrane $\mathrm{Ca}^{2+}$ extrusion by the high-affinity Ca-Mg-ATPase (and/or $\mathrm{Na}$ :Ca exchange) or may serve as a signal for these or other processes.

Our estimates of the roles of bath and lumen $\mathrm{Ca}$ in the PTH-induced rise in $\left[\mathrm{Ca}^{2+}\right]_{\mathrm{i}}$ must be considered tentative for two reasons. First, our approach to correct for the effect of lumen $\mathrm{Ca}$ deletion and for the transient overshoot in $\left[\mathrm{Ca}^{2+}\right]_{i}$ during acute $\mathrm{Ca}$ repletion is only a first approximation. Second, the deionized water used to prepare the nominally $0-\mathrm{mM}$ Ca perfusate was estimated to contain $0.9 \mu \mathrm{M} \mathrm{Ca}$, so that the increment in $\left[\mathrm{Ca}^{2+}\right]_{i}$ assigned to bath $\mathrm{Ca}$ may be an overestimate.

Similar to other renal epithelia $(14,16,19,23)$, we observed that media $\mathrm{Ca}$ deletion rapidly and markedly reduced $\left[\mathrm{Ca}^{2+}\right]_{\mathrm{i}}$ in the CNT, with a mean fall of $\sim 80 \mathrm{nM}$ (Fig. 6). Eliminating perfusate $\mathrm{Ca}$ while keeping suffusate [Ca] at $2 \mathrm{mM}$ attentuated this fall in $\left[\mathrm{Ca}^{2+}\right]_{i}(44-50 \mathrm{nM}$; Table I and Fig. 8), implying that $\mathrm{Ca}$ influxes across both apical and basolateral plasma membranes are important in regulating $\left[\mathrm{Ca}^{2+}\right]_{i}$ in the CNT. Without media $\mathrm{Ca}$, PTH had no effect on $\left[\mathrm{Ca}^{2+}\right]_{i}$ (Fig. 6), mitigating against release of $\mathrm{Ca}$ from intracellular stores.

In conclusion, this study demonstrates that physiological concentrations of PTH cause a significant increase in $\left[\mathrm{Ca}^{2+}\right]_{i}$ in cells of the rabbit CNT. This action is mimicked by $8-\mathrm{Br}-$ cAMP, implicating cAMP as an intracellular messenger. The PTH-stimulated rise in $\left[\mathrm{Ca}^{2+}\right]_{i}$ depends on extracellular fluid $\mathrm{Ca}$, with bath and tubular luminal fluids both playing important roles.

\section{Acknowledgments}

We thank Mohammed I. Ahmed and Dawn L. Sadowski for technical assistance and Katrina N. Williams for secretarial support. We are grateful to Dr. P. Darwin Bell of the University of Alabama in Birmingham for valuable guidance and encouragement in setting up our fluorescence microscopy laboratory. Thanks are also due to $\mathrm{Dr}$. Matthew Breyer of Vanderbilt University for suggestions regarding the heated infusion line. We are grateful to Bonnie Eby for data analysis.

This work was supported in part by grants from the National Institute of Diabetes and Digestive and Kidney Diseases (DK-33507 and DK-35985), the Chicago Heart Association, and the American Heart Association (84-1296 and 87-956), and by an Established Investigator Award from the American Heart Association (to Dr. Bourdeau) and a Research Career Development Award from the National Institutes of Health (to Dr. Lau).

\section{References}

1. Shareghi, G. R., and L. C. Stoner. 1978. Calcium transport across segments of the rabbit distal nephron in vitro. Am. J. Physiol. 235:F367-F375.

2. Imai, M. 1981. Effects of parathyroid hormone and $\mathrm{N}^{6}, \mathrm{O}^{21}-\mathrm{di}-$ butyryl cyclic AMP on $\mathrm{Ca}^{2+}$ transport across the rabbit distal nephron segments perfused in vitro. Pfluegers Arch. Eur. J. Physiol. 390:145151.

3. Bourdeau, J. E. 1983. Renal handling of calcium. In Divalent Ion Homeostasis (Contemporary Issues in Nephrology, Vol. 11). B. M. Brenner and J. H. Stein, editors. Churchill Livingstone, Inc. New York. 1-31.

4. Marx, S. J., and J. E. Bourdeau. 1987. Calcium metabolism. In Clinical Disorders of Fluid and Electrolyte Metabolism. M. H. Maxwell, C. R. Kleeman, and R. G. Narins, editors. 4th ed. McGraw-Hill Book Company, New York. 207-244.

5. Chabardes, D. M., M. Imbert, A. Clique, M. Montegut, and F. Morel. 1975. PTH sensitive adenyl cyclase activity in different segments of the rabbit nephron. Pfluegers Arch. Eur. J. Physiol. 354:229239.

6. Bourdeau, J. E., R. Bouillon, D. Zikos, and C. B. Langman. 1988. Renal responses to calcium deprivation in young rabbits. Miner. Electrolyte Metab. 14:150-157.

7. Bourdeau, J. E. 1986. Calcium transport across the pars recta of cortical segment 2 proximal tubules. Am. J. Physiol. 251:F718-F724.

8. Tsien, R. Y., T. J. Rink, and M. Poenie. 1985. Measurement of cytosolic free $\mathrm{Ca}^{2+}$ in individual small cells using fluorescence microscopy with dual excitation wavelengths. Cell Calcium. 6:145-157.

9. Burg, M., J. Grantham, M. Abramow, and J. Orloff. 1966. Preparation and study of fragments of single rabbit nephrons. Am. J. Physiol. 210:1293-1298.

10. Burg, M. B. 1972. Perfusion of isolated renal tubules. Yale J. Biol. Med. 45:321-326.

11. Grynkiewicz, G., M. Poenie, and R. Y. Tsien. 1985. A new generation of $\mathrm{Ca}^{2+}$ indicators with greatly improved fluorescence properties. J. Biol. Chem. 260:3440-3450.

12. Winer, B. J. 1971. Statistical Principles in Experimental Design. 2nd ed. McGraw-Hill Book Company, New York. 907 pp.

13. Snedecor, G. W., and W. G. Cochran. 1967. Statistical Methods. 6th ed. Iowa State University Press, Ames, IA. 593 pp.

14. Hruska, K. A., M. Goligorsky, J. Scoble, M. Tsutsumi, S. Westbrook, and D. Moskowitz. 1986. Effects of parathyroid hormone on cytosolic calcium in renal proximal tubular primary cultures. Am. J. Physiol. 251:F188-F198.

15. Bonventre, J. V., K. L. Skorecki, J. I. Kreisberg, and J. Y. Cheung. 1986. Vasopressin increases cytosolic free calcium concentration in glomerular mesangial cells. Am. J. Physiol. 251:F94-F102.

16. Hassid, A., N. Pidikiti, and D. Gamero. 1986. Effects of vasoactive peptides on cytosolic calcium in cultured mesangial cells. Am. J. Physiol. 251:F1018-F1028.

17. Bonventre, J. V., and J. Y. Cheung. 1986. Cytosolic free calcium concentration in cultured renal epithelial cells. Am. J. Physiol. 250:F329-F338.

18. Cheung, J. Y., J. M. Constantine, and J. V. Bonventre. 1986. 
Regulation of cytosolic free calcium concentration in cultured renal epithelial cells. Am. J. Physiol. 251:F690-F701.

19. Goligorsky, M. S., D. J. Loftus, and K. A. Hruska. 1986. Cytoplasmic calcium in individual proximal tubular cells in culture. Am. J. Physiol. 251:F938-F944.

20. Hruska, K. A., D. Moskowitz, P. Esbrit, R. Civitelli, S. Westbrook, and M. Huskey. 1987. Stimulation of inositol trisphosphate and diacylglycerol production in renal tubular cells by parathyroid hormone. J. Clin. Invest. 79:230-239.

21. Dolson, G. M., M. K. Hise, and E. J. Weinman. 1985. Relationship among parathyroid hormone, cAMP, and calcium on proximal tubule sodium transport. Am. J. Physiol. 249:F409-F416.

22. Murphy, E., M. E. Chamberlin, and L. J. Mandel. 1986. Effects of calcitonin on cytosolic $\mathrm{Ca}$ in a suspension of rabbit medullary thick ascending limb tubules. Am. J. Physiol. 251:C491-C495.

23. Yanagawa, N. 1987. Cytosolic free calcium in isolated perfused rabbit proximal tubules: effect of parathyroid hormone. Kidney Int. 31:361a.(Abstr.)

24. Bourdeau, J. E., C. B. Langman, and R. Bouillon. 1987. Parathyroid hormone-stimulated calcium absorption in CTAL from vitamin D-deficient rabbits. Kidney Int. 31:913-917.

25. Teitelbaum, I., and T. Berl. 1986. Effects of calcium on vasopressin-mediated cyclic adenosine monophosphate formation in cultured rat inner medullary collecting tubule cells. Evidence for the role of intracellular calcium. J. Clin. Invest. 77:1574-1583.

26. Filburn, C. R., and S. Harrison. 1987. Parathyroid hormone stimulation of cytosolic $\mathrm{Ca}^{2+}$ in the rat renal proximal tubule. Kidney Int. 31:346a.(Abstr.)

27. Borle, A. B., and T. Uchikawa. 1978. Effects of parathyroid hormone on the distribution and transport of calcium in cultured kidney cells. Endocrinology. 102:1725-1732.

28. Borle, A. B., and T. Uchikawa. 1979. Effects of adenosine $3^{\prime}, 5^{\prime}$-monophosphate, dibutyryl adenosine 3 ',5'-monophosphate, aminophylline, and imidazole on renal cellular calcium metabolism. Endocrinology. 104:122-129.

29. Yamaguchi, D. T., T. J. Hahn, A. Iida-Klein, C. R. Kleeman, and S. Muallem. 1987. Parathyroid hormone-activated calcium channels in an osteoblast-like clonal osteosarcoma cell line: cAMP-dependent and cAMP-independent calcium channels. J. Biol. Chem. 262:7711-7718.
30. Nagata, N., and H. Rasmussen. 1970. Parathyroid hormone, 3'5'-cAMP, $\mathrm{Ca}^{++}$, and renal gluconeogenesis. Proc. Natl. Acad. Sci. USA. 65:368-374.

31. Goligorsky, M. S., D. N. Menton, and K. A. Hruska. 1986. Parathyroid hormone-induced changes of the brush border topography and cytoskeleton in cultured renal proximal tubular cells. J. Membr. Biol. 92:151-162.

32. Pollack, A. S., D. G. Warnock, and G. J. Strewler. 1986. Parathyroid hormone inhibition of $\mathrm{Na}^{+}-\mathrm{H}^{+}$antiporter activity in a cultured renal cell line. Am. J. Physiol. 250:F217-F225.

33. McKinney, T. D., and P. Myers. 1980. Bicarbonate transport by proximal tubules: effect of parathyroid hormone and dibutyryl cyclic AMP. Am. J. Physiol. 238:F166-F174.

34. Bourdeau, J. E., and M. B. Burg. 1980. Effect of PTH on calcium transport across the cortical thick ascending limb of Henle's loop. Am. J. Physiol. 239:F121-F126.

35. Suki, W. N., and D. Rouse. 1981. Hormonal regulation of calcium transport in thick ascending limb renal tubules. Am. J. Physiol. 241:F171-F174.

36. Shareghi, G. R., and Z. S. Agus. 1982. Magnesium transport in the cortical thick ascending limb of Henle's loop of the rabbit. J. Clin. Invest. 69:759-769.

37. Constanzo, L. S., and E. E. Windhager. 1980. Effects of PTH, $\mathrm{ADH}$, and cyclic AMP on distal tubular $\mathrm{Ca}$ and $\mathrm{Na}$ reabsorption. Am. J. Physiol. 239:F478-F485.

38. Yanagawa, N., and O. D. Jo. 1986. Possible role of calcium in parathyroid hormone actions in rabbit renal proximal tubules. Am. J. Physiol. 250:F942-F948.

39. Constanzo, L. S., and E. E. Windhager. 1978. Calcium and sodium transport by the distal convoluted tubule of the rat. Am. J. Physiol. 235:F492-F506.

40. Lau, K., S. Goldfarb, M. Goldberg, and Z. S. Agus. 1982. Effects of phosphate administration on tubular calcium transport. $J$. Lab. Clin. Med. 99:317-324.

41. Lau, K., Z. S. Agus, M. Goldberg, and S. Goldfarb. 1979. Renal tubular sites of altered calcium transport in phosphate-depleted rats. $J$. Clin. Invest. 64:1681-1687.

42. Constanzo, L. S. 1985. Localization of diuretic action in microperfused rat distal tubules: $\mathrm{Ca}$ and $\mathrm{Na}$ transport. Am. J. Physiol. 248:F527-F535. 